\title{
ORGANIZAÇÕES DE ENSINO SUPERIOR: INCLUSÃO E AMBIENTE DE TRABALHO*
}

\author{
Carlos Eduardo Candido Pereira ${ }^{1}$ \\ José Luís BIZELLI ${ }^{2}$ \\ Lúcia Pereira Leite ${ }^{3}$
}

\begin{abstract}
RESUMO: Pessoas com deficiência ingressam no mercado de trabalho para realizar atividades produtivas e construir sua independência. $\mathrm{O}$ avanço da legislação não impede dificuldades de ingresso e permanência nas organizaçôes laborais. Nesta investigaçáo, o campo escolhido foi uma universidade pública. Os participantes foram servidores técnico-administrativos e docentes com deficiência, que opinaram sobre a sua experiência de ingresso e as condiçóes de trabalho que lhe foram oferecidas na instituição. As análises revelam o despreparo da organização no momento de receber o trabalhador; o preconceito e a discriminaçáo no trato com colegas e chefias e a indiferença à lei. Apesar das condiçóes materiais existentes, há uma valorização e motivação dos servidores para ter acesso ao emprego.
\end{abstract}

Palavras-chave: Inclusão. Ensino Superior. Mercado de trabalho.

\section{HigHER EDUCATION ORgANIZATIONS: INCLUSION AND WORK ENVIRONMENT}

\begin{abstract}
People with disabilities enter the labor market to carry out productive activities and build their independence. The advance of legislation does not preclude difficulties in entering and remaining in labor organizations. In this investigation, the chosen field was a public university. Participants were technical and administrative staff and teachers with disabilities, who reported on their entry experience and working conditions that were offered at the institution. The analysis reveals the unpreparedness of the organization at the time of receiving the workers; the prejudice and discrimination in dealing with colleagues and managers; and indifference to the law. Despite the existing material conditions, servants show appreciation and motivation for having access to employment.
\end{abstract}

Keywords: Inclusion. Higher Education. Labor market.

\footnotetext{
*Artigo resultado do Projeto de Pesquisa "Acessibilidade no Ensino Superior: da análise das políticas públicas educacionais ao desenvolvimento de mídias instrumentais sobre deficiência e inclusão", pesquisa em rede financiada pela Coordenaçáo de Aperfeiçoamento de Pessoal de Nível Superior (CAPES) aprovada no Edital Observatório Em Educação (OBEDUC- Edital 49/2012 - Proc. 8224/12).

${ }^{1}$ Universidade Estadual Paulista "Júlio de Mesquita Filho" (UNESP), Faculdade de Ciências e

Letras, Programa de Pós-graduação em Educação Escolar - Araraquara (SP), Brasil.

E-mail: candido_unesp@yahoo.com.br

${ }^{2}$ UNESP, Faculdade de Ciências e Letras, Departamento de Antropologia Política, Programa de Pós-graduação em Educação Escolar - Araraquara (SP), Brasil. E-mail: bizelli@fclar.unesp.br ${ }^{3}$ UNESP, Faculdade de Ciências, Departamento de Psicologia, Programa de Pós-graduaçáo em Psicologia do Desenvolvimento e da Aprendizagem - Bauru (SP), Brasil. E-mail: lucialeite@fc.unesp.br DOI: 10.1590/ES0101-73302017151511
} 


\title{
ÉTABLISSEMENTS D'ENSEIGNEMENT SUPERIEUR : INCLUSION ET DE L'ENVIRONNEMENT DE TRAVAIL
}

\begin{abstract}
RÉSUMÉ: Les personnes handicapées entrent sur le marché du travail pour mener à bien des activités productives et de construire leur indépendance. L'avance de la législation ne l'empêche pas d'entrée de difficultés et est resté dans les organisations syndicales. Dans cette enquête, le domaine choisi est une université publique. Les participants étaient personnel technique et administratif et les enseignants handicapées, qui disent à propos de leur expérience de l'entrée et les conditions de travail qui ont été offerts à l'établissement. Les analyses révèlent l'impréparation de l'organisation au moment de recevoir le travailleur ; les préjugés et la discrimination dans le traitement avec des collègues et des gestionnaires; indifférence à la loi. Malgré les conditions matérielles existantes il ya une appréciation et la motivation des serveurs d'avoir accès à l'emploi.
\end{abstract}

Mots-clés: Inclusion. Enseignement Supérieur. Travailler marché.

\section{Introdução}

A

inclusão de pessoas com deficiências na sociedade moderna não é tema recente. Todavia, há certa complexidade na construção social para garantir a participaçáo de segmentos populacionais diversos, quando se pensa na capacidade de o Governo produzir políticas públicas que caminhem no sentido da equidade (RAWLS, 1997; SEN, 2001).

Numa digressão histórica, vale destacar que, no século XX, regimes de Governo, oriundos de concepçóes iluministas, se solidificaram. Em paralelo, o capitalismo se consagrou como sistema produtivo preponderante. O trabalho, anteriormente artesanal, passou a ser substituído, gradualmente, pela máquina. De modo sintético, essa mudança de produção, que recebeu o nome de Revolução Industrial, causou impactos em vários aspectos na vida dos sujeitos, seja de modo particular ou coletivo.

Naquele contexto, bem como em outros (MAZZOTTA, 2005), a pessoa com deficiência era marginalizada. Não havia a perspectiva de que ela pudesse ser produtiva ou que pudesse ter condiçóes de operar máquinas. A cultura da deficiência, o estigma e o preconceito acabaram por tolher a participação desses sujeitos em todos os estratos sociais.

No âmbito do trabalho, esse cenário passou a ter mudança em virtude das alteraçóes no modus operandi dos sistemas produtivos, atrelado às mudanças nos sistemas organizacionais provocadas pela inovação tecnológica e pela 
entrada das teorias científicas da administração no cotidiano das instituiçóes. Tais fatores propiciaram mudanças de perspectiva às pessoas com deficiência, porém, de maneira gradual.

As teorias das ciências administrativas, sobretudo aquelas pautadas nas relaçôes humanas, implicaram em maior sensibilidade aos sujeitos. Com o advento de organizaçôes representativas e sindicatos, a questão do direito do trabalho e da defesa dos interesses do trabalhador foi ganhando destaque. Nesse ponto, é possível identificar o cuidado à condição de deficiência, em virtude de que o próprio mercado laboral contribuía para o aumento de pessoas em situação de limitação física ou sensorial, uma vez que era progressivo, por falta de condiçóes de segurança, o aumento de sujeitos acidentados em serviço, alguns adquirindo limitação temporária ou mesmo deficiência permanente, originando muitas vezes a posiçáo social de invalidez em decorrência da incapacidade para o trabalho.

Dado o exposto, ainda no século XX, o período de guerras, segundo Dall'Acqua (2002), provocou um número sem fim de vítimas e de mutilaçóes, o que contribuiu para o aumento significativo no percentual de pessoas com deficiências. Ao retornar da guerra para suas casas, muitos eram vistos como heróis, outros, porém, necessitavam retornar ao trabalho para manutençáo pessoal ou mesmo familiar.

No período pós-guerra, a sociedade ainda não estava estruturalmente ajustada para receber a deficiência. Somado a isso, com uma demanda cada vez maior desse público e com a distância entre os direitos e deveres das pessoas com deficiências, tornou-se pertinente que elas reivindicassem os seus direitos. Assim, uma série de conquistas no âmbito legal foi obtida na onda de movimentos sociais se organizarem e clamarem por seus direitos. Dito de outro modo, tinha-se um expressivo contingente populacional, pós-guerra, debilitado e traumatizado, que apontava para a necessidade da reabilitação profissional, dando novos contornos às expectativas profissionais.

A educação, nesse contexto, sobretudo, tinha por responsabilidade preparar cada vez mais mentes pensantes para a promoção da qualidade dos serviços. O capital cultural se tornou fator preponderante aos postos de trabalho. Tal aspecto ganhou força com as políticas neoliberais e a globalização no final do século XX.

Dessa maneira, no século passado, as sequelas provocadas pelas mudanças nos sistemas produtivos e as açôes bélicas colocaram definitivamente em pauta a inclusão de pessoas com deficiência, exigindo novas abordagens para o tema e políticas públicas mais adequadas. Do ponto de vista legal, garantiu-se a participação da pessoa com deficiência nas vidas social e produtiva.

A construçáo histórica do significado, das interpretaçóes e dos questionamentos sobre o conceito de inclusão consolida um movimento que prevê a participaçáo efetiva de segmentos sociais que estiveram no entorno, na garantia da 
ocupação de diversos locais pelo emprego do adjetivo, como é o caso da "educação inclusiva", da "organização inclusiva", do "transporte inclusivo", dentre outros. Descreve-se uma nítida trajetória entre as expectativas sociais para com a pessoa imperfeita, ou possuída pelo demônio (BIANCHETTI, 1998), e as expectativas sociais para com o cidadão de direitos (BOBBIO, 1992), o que dá origem a diferentes instituiçôes de serviços especiais e de acolhimento - de Santas Casas de Misericórdia a Associaçóes Especializadas, revestidas do caráter filantrópico no atendimento institucionalizado (MAZZOTTA, 2005).

Incluir, porém, não muda o preconceito ou o estigma que recai sobre as pessoas com deficiências, pois são marcadas negativamente na sociedade, por apresentarem características físicas, sensoriais, intelectuais e/ou comportamentais diferentes, ou seja, que destoam de um ideal de perfeição humana (Goffmann, 1988). Muito embora a civilização da convivência nas sociedades complexas da modernidade permita, pela promoção de açóes repressivas do Governo, cercear o desrespeito às diferenças, a inclusão ainda é um exercício cotidiano de vencer preconceitos socialmente estabelecidos.

No campo econômico, a situação não é diferente. A absorção da pessoa com deficiência no mercado de trabalho enfrenta em igual medida a intolerância à diferença. Se no início da sociedade capitalista o trabalho teve um sentido mais incisivo na doutrinação dos corpos - território menos favorável à competição para pessoas com deficiências —, as fases ulteriores da acumulação capitalista, baseadas em trabalho mais elaborado, abriram maiores possibilidades de posto de trabalho. Isso não significa, porém, que encontrar um trabalho digno e produtivo com remuneração suficiente para a manutenção pessoal seja tarefa simples.

A pressão de organismos e acordos internacionais tem contribuído significativamente para o processo de inclusão. Assim, o exemplo da Organização Internacional do Trabalho - que, a partir dos anos 1980, recomenda aos empregadores a abertura de vagas para as pessoas com deficiências, conferindo-lhes e qualificando-os como sujeitos com capacidades laborais - e da Conferência Mundial de Educação para Todos (UNESCO, 1990) e da Declaração de Salamanca (UNESCO, 1994), ao conferirem um caráter inclusivo dentro dos sistemas de ensino, dá alento para aqueles que buscam um ensino aberto às diferenças e um mercado de trabalho menos preconceituoso no que se refere ao trato com as pessoas com deficiências. No Brasil, a Constituição Federal de 1998 passou a dispensar tratamento diferenciado aos indivíduos com deficiência, tanto em termos educacionais como na esfera laboral. Ao reconhecer a deficiência como uma diferença, abre-se uma série de prerrogativas constitucionais na garantia de seus direitos.

No entanto, mesmo com açóes governamentais, é ainda atribuído à pessoa com deficiência o status de improdutiva, ineficiente ou, ainda, incapaz — adjetivações de uma sociedade em que o capital se sobrepóe às condiçóes humanas. Atrelada aos fatores político-econômicos, tem-se a imagem corporal da pessoa com deficiência, 
distante da ideia de homem valorada positivamente (AMARAL, 1998). Para Pereira e Passerino (2012), a empregabilidade de pessoas com deficiência se configura num fenômeno complexo e heterogêneo, por envolver variáveis conflitantes, pois ao se pensar em promover a inclusão social, faz-se necessário reconhecer a exclusão como parte integrante das contradiçóes do sistema capitalista, atrelado à complexidade da natureza humana e das esferas sociais estruturadas pelos próprios homens.

Diante das discussóes postas, o objeto de análise deste trabalho se configura na intrínseca relação entre educação e mercado de trabalho, nas sociedades capitalistas, quando tratamos especificamente de incluir pessoas com deficiências. Num mundo que se especializa cada vez mais e com maior rapidez, como ser produtivo para além de limitaçóes físicas, sensoriais e mesmo psicossociais? Não escolhemos para esta investigação o universo de trabalho como um todo, mas focamos em um segmento muito específico e esclarecido: uma universidade pública. Além disso, não foram tomados dados estatísticos agregados que nos distanciassem de nossos atores, trabalhamos com questionários e entrevistas na busca da percepçáo das pessoas com deficiência sobre o seu ambiente de trabalho.

Diante dos conceitos colocados por Habermas (1998), se a legislação brasileira cada vez mais dá "facticidade" aos avanços das políticas de inclusão na educação e no mercado de trabalho para uma pessoa com deficiência, o que dará a "validade" para seu acesso e permanência no mundo laboral?

\section{Da relação entre a escola e o trabalho}

Para Dourado e Oliveira (1999), a educação tem duas tarefas básicas: conhecimento e formação, as quais são essenciais para inserção de qualquer país no processo competitivo do mundo globalizado. Nas palavras dos autores:

Assim, o investimento em cérebros, ou melhor, na criação de capital intelectual e na formação de competências básicas permitiria tornar a economia competitiva, uma vez que vivemos em uma sociedade marcada, crescentemente, pela internacionalização produtiva, pelo aumento dos conhecimentos técnicos-científicos e pela necessidade de elevação de qualidade profissional (DOURADO; OLIVEIRA, 1999, p. 12).

O mundo do trabalho contemporâneo é o norteador das habilidades e competências que devem estar contidas nos sistemas educativos, em seus diversos níveis. Há, segundo Ross (2006), uma complementaridade ${ }^{1}$ entre o espaço da educaçáo e o do trabalho, exigindo que o processo educativo esteja constantemente revendo seus currículos, suas açóes metodológicas e as práticas docentes para que a escola não fique alheia à realidade do trabalho globalizado. Como entáo inserir na escola a educação inclusiva? 
Vale lembrar que a legislação que orienta a implantação de um sistema inclusivo é recente no Brasil, datada dos anos 1990. Estudos mais atuais procuram em alguma medida traçar aproximaçóes entre as trajetórias escolares e o trabalho com pessoas com deficiência. Candido Pereira (2010, p. 150), investigando a percepção de pessoas com deficiências intelectual, auditiva, visual e física sobre o ambiente de trabalho na indústria brasileira, identificou que:

\section{[...]}

A) No que se refere à educaçáo - 1 . A maioria dos respondentes concorda que deveriam estudar na escola comum; 2. A escola comum não está preparada para atender pessoas com deficiências; 3. Há preconceito e discriminação no ambiente escolar; 4. Docentes e metodologias de ensino não estáo adaptados ao público-alvo deste estudo;

B) No que se refere ao mercado de trabalho - 1 . Escolaridade não garante ingresso no mercado de trabalho; 2 . Pessoas com deficiências têm dificuldades adicionais para encontrar trabalho; 3. Mesmo assim, o mercado de trabalho se aprimora mais rapidamente para incluir do que a escola; 4 . A lei de cotas ainda é a maior garantia de inclusão no mercado de trabalho; 5 . Há barreiras para que a pessoa com deficiência chegue a bons cargos; 6. O trabalho é importante para a aquisição de independência financeira e para a melhoria da vida do indivíduo; 7 . O trabalho ensina mais do que a escola.

Os dados mostram um cenário que caminha lentamente para a consolidação das políticas inclusivas, muito embora haja dificuldades e dilemas, seja no ambiente escolar ou no laboral, respeitadas as ações e os que são diferentes.

O trabalho é o cerne da vida nas sociedades capitalistas. Quando se trabalha com pessoas com deficiência, é preciso qualificar segmentos ou nichos, onde existem colocações profissionais que possam ser disputadas. Um primeiro nicho é aquele que coloca lado a lado pessoas com ou sem deficiências disputando postos de trabalho. O segmento competitivo, certamente, é aquele em que se exige maior especialização, educativa e laboral.

Outro nicho é a colocação seletiva, que requer o auxílio de apoios especiais:

$\mathrm{Na}$ colocação seletiva, a contratação de pessoas com deficiência dependerá, para viabilizar-se, da utilizaçáo de procedimentos e apoios especiais, que também devem observar as exigências da legislação trabalhista e previdenciária. [...] Algumas deficiências não permitem que a pessoa realize uma ocupação sem o estabelecimento de condições facilitadoras, tais como jornada variável, horários flexíveis de trabalho e adequação do ambiente de trabalho às suas especificidades (MIRANDA, 2006, p. 163). 
Um terceiro nicho é o trabalho por conta própria, que pode ser desenvolvido de forma autônoma, ou cooperativa, ou em regime de economia familiar. Faz parte desse segmento o trabalho realizado em entidades assistenciais, na roupagem de instituiçôes não governamentais, com a intenção de gerir para o indivíduo ou, ainda, melhorar as condiçóes de bens de usufruto coletivo.

O quarto nicho provém das conquistas legais que visam colocar pessoas com deficiências no mercado de trabalho (MIRANDA, 2006). Assim,

[...] as últimas décadas marcaram um tempo de grandes esforços legislativos com vista a melhor integrar as pessoas com deficiência no mercado de trabalho e, atualmente, a finalidade primordial da política de emprego é a inserção deste contingente nas diversas categorias do mundo do trabalho (PASTORE, 2000, p. 34).

No que se refere especificamente à empregabilidade de pessoas com deficiência no mercado privado de trabalho, tem-se a Lei 8.213/91, conhecida como Lei de Cotas (BRASIL, 1991), que trabalha com a obrigatoriedade da contratação de pessoas com deficiência de acordo com o tamanho da empresa: de 2 a $5 \%$ em empresas que váo de 100 a mais de 1.000 empregados. A penalidade prevista pelo descumprimento é a multa, e a fiscalização é feita pelo auditor fiscal do trabalho, que participa de equipes compostas por outros profissionais: médicos do trabalho, engenheiros de segurança de trabalho e advogados.

Nos casos em que não é possível a inclusão da pessoa com deficiência no mercado de trabalho, há a possibilidade de recebimento do Benefício de Prestação Continuada (BPC), criado em 1993 (BRASIL, 1993). O BPC é a transferência incondicional de renda, no valor de um salário-mínimo mensal, para idosos ou pessoas com deficiência, em situação de pobreza, quando a renda familiar per capita é inferior a um quarto de salário-mínimo.

Embora o setor público também tenha que cumprir a legislação que garanta a participaçáo de pessoas com deficiência, a ênfase se dá nos procedimentos de ingresso, ou seja, nas especificaçóes dos editais de concurso de ingresso. O Decreto Federal no 3.298 (BRASIL, 1999) regulamenta o acesso ao trabalho público por pessoas com deficiências:

[...] Art. 37. Fica assegurado à pessoa portadora de deficiência o direito de se inscrever em concurso público, em igualdade de condiçóes com os demais candidatos, para provimento de cargo cujas atribuiçóes sejam compatíveis com a deficiência de que é portador.

$\$ 1^{\circ} \mathrm{O}$ candidato portador de deficiência, em razão da necessária igualdade de condiçóes, concorrerá a todas as vagas, sendo reservado no mínimo o percentual de cinco por cento em face da classificação obtida. 
$\$ 2^{\circ}$ Caso a aplicação do percentual de que trata o parágrafo anterior resulte em número fracionado, este deverá ser elevado até o primeiro número inteiro subsequente. (BRASIL, 1999, p. 7-8).

O espírito da legislação citada é criar condições equânimes para a disputa do posto de trabalho, garantindo a permanência e a substituição do funcionário, mantidas as proporções legalmente previstas; dando detalhes sobre o funcionamento do concurso público e especificando a equipe multiprofissional que deve apoiar o candidato nas provas e o profissional no ambiente de trabalho. Em outros termos, nas políticas públicas, configura-se como dever do Estado brasileiro programar e efetivar projetos de Governo, pelo intermédio da oferta de programas e/ou açóes voltadas para o atendimento de setores específicos da sociedade (e/ou segmentos populacionais diferenciados), na forma de políticas sociais que

se referem a açôes que determinam o padrão de proteção social implementado pelo Estado, voltadas, em princípio, para a redistribuição dos benefícios sociais visando à diminuição das desigualdades estruturais produzidas pelo desenvolvimento socioeconômico (HÖFLING, 2001, p. 31).

No caso aqui retratado, são ações voltadas para a garantia das condiçóes de trabalho às pessoas com deficiência em organizações governamentais.

\section{Da investigação e dos seus resultados}

A pesquisa foi realizada em universidade pública no estado de São Paulo, regida, portanto, pela Lei Complementar no 683 (SÃO PAULO, 1992), a qual dispóe que, para qualquer concurso público estadual, sejam previstas $5 \%$ de vagas para pessoas com deficiência. Na prática, os procedimentos adotados seguem a seguinte sistemática: realizado o concurso, os classificados são dispostos em duas listas, atendendo à situação "com" ou "sem" deficiências. No momento de chamar os candidatos aprovados, a cada quatro pessoas sem deficiência, convoca-se uma com deficiência.

A universidade estudada conta com 37 unidades, espalhadas em 24 cidades, sendo 22 delas no interior, 1 na capital e 1 no litoral. Segundo seu anuário, referente a 2014 , havia 3.730 docentes em atividade e 7.427 técnicos administrativos ativos. Com relação aos trabalhadores com algum tipo de deficiência, identificou-se, junto à administração, a inexistência de dados precisos sobre a questão, quer nas fichas funcionais dos servidores, quer nos laudos resultantes dos exames laborais periódicos. A fonte de informação que passamos a considerar foi a unidade administrativa local, já que está mais próxima das fontes de dados que interessavam a este estudo. 
Das seçôes ou departamentos das 37 unidades - as quais foram contatadas por ofício -, 12 responderam prestando as devidas informaçôes. As fontes foram a autodeclaraçáo dos funcionários ou os registros administrativos dos que ingressaram pelas cotas. Cada unidade, em verdade, organizou-se de forma diferente para levantar e organizar os dados, o que deixa patente a falta de regras e procedimentos padrōes para tratar da questão. Foram identificadas, então, 34 pessoas com deficiências, sendo que das 21 que aceitaram participar do estudo, 13 apresentavam deficiência física (62\%), 7 apresentavam deficiência visual (33\%) e 1 tinha deficiência auditiva (5\%). Nenhum dos participantes possuía deficiência intelectual ou múltipla; 18 deles (86\%) relataram ter adquirido a deficiência, com maior incidência, em acidentes. Nesse sentido, Lopes e Leite (2015) indicam que a aquisição da deficiência é entendida como um agente transformador da história do sujeito que se encontra nessa condiçáo, e no campo do trabalho novas demandas surgem, somadas - na esfera individual - à necessidade de superaçáo na nova condição imposta.

Ainda em termos amostrais, dos participantes - funcionários públicos da autarquia estadual —, 5 atuavam como docentes e 16 atuavam na qualidade de servidores técnico-administrativos. Desse universo, mais da metade era composta de homens com escolaridade majoritariamente em grau superior. Quanto ao tempo de ingresso na universidade, um total de 15 participantes está no exercício da atividade aproximadamente por 10 anos, ao passo que 6 possuem entre 20 e 30 anos de trabalho. Tal dado pode ser atrelado ao argumento de que, em razão das medidas legais protetivas, como o citado Decreto Federal no 3.298/1999 (BRASIL, 1999), houve aumento do público com deficiência no setor público nos últimos 20 anos.

A abordagem com os participantes foi realizada por mensagem eletrônica e/ou telefone, fornecidos pelo setor de recursos humanos da instituição. Após a carta-convite e o aceite formalizado, foi enviado o questionário, que contemplava cinco itens de investigação: (a) caracterização do participante; (b) conhecimento geral - noção que os participantes têm da deficiência, sobretudo, por meio das normativas; (c) trajetória escolar; (d) mercado de trabalho e o trabalho na universidade; (e) expressôes voluntárias - espaço destinado aos participantes para manifestarem suas impressōes de modo aberto e livre.

Sobre os conhecimentos referentes às leis para as pessoas com deficiência, houve o relato de conhecerem em maior incidência: a Lei de Cotas (BRASIL, 1991), a Lei Estadual no 683 (SÃO PAULO, 1992), o Decreto Federal no 3.298 (BRASIL, 1999) e a Lei de Acessibilidade (BRASIL, 2000). O público participante, por sua vez, demonstra bom conhecimento de legislaçóes importantes para as necessidades das pessoas com deficiências. Isso, talvez, esteja atrelado ao nível de instrução exigido para ingresso na função/cargo.

Para quase a totalidade dos participantes, a reserva de vagas ainda é o único recurso válido para ingresso no trabalho do setor público. Apesar disso, 
entre a maioria $(75 \%)$ há a discordância sobre a pessoa com deficiência só obter oportunidade de trabalho, no setor privado, por meio da Lei de Cotas (BRASIL, 1991). Trata-se de um resultado provocado por mudança na cultura do Brasil nos últimos anos e também pelo emprego do empowerment, cada vez mais presente no cotidiano desse público. Martins e Leite (2014, p. 191), ao revisar esse conceito, destacam que, embora inicialmente na realidade brasileira

tivesse sido traduzido como empoderamento, vários pesquisadores têm optado por mantê-lo na escrita da palavra original em inglês, com destaque à compreensão do conceito como sinônimo de possibilidades da pessoa com deficiência assumir o controle da própria vida

com vistas à sua autonomia social. As autoras resgatam o estudo de Souza et al. (2006, p. 266-267), que o definem como a provisão de conhecimentos e habilidades ofertada aos sujeitos, com vistas a uma compreensão crítica das relaçôes sociais e das contingências políticas, na busca da conquista da cidadania.

Retomando as consideraçóes dos participantes, percebemos que, para a maioria, a esfera privada está em melhor condição de recepção da pessoa com deficiência em oposição ao setor público. Em ambos os setores, porém, ainda há preconceito e discriminação. Tais barreiras são apontadas por $90 \%$ dos participantes que relatam sua ocorrência pelo desconhecimento da deficiência ou mesmo pela desconfiança ao potencial que tem. A melhoria de tais condiçóes poderia ocorrer em virtude de mais espaço para a manifestação da própria pessoa com deficiência sobre as suas reais necessidades especiais.

Pelo intermédio dos dados, é possível delinear a percepção dos respondentes quanto ao universo escola/trabalho. É unânime, por exemplo, o reconhecimento de que sem as leis que fomentam a educação inclusiva, eles possivelmente não teriam alavancado níveis mais elevados de ensino e, consequentemente, sucesso na sua vida laboral. A percepção é que teriam sido marginalizados em ambos os processos.

Quando questionados sobre a importância da escola em sua trajetória para a obtenção do emprego, pouco mais da metade (52\%) concorda que a educação formal, por si só, não garante ingresso da pessoa com deficiência no mercado de trabalho. Há, portanto, necessidade de algum tipo de formação complementar à escola para competir no mercado de trabalho, tal como cursos de formação técnica ou profissional.

Se, por um lado, quando perguntados sobre a capacidade educativa da escola e do ambiente de trabalho, evidenciou-se uma percepção mais positiva para a importância do trabalho, por outro, 90\% da amostra revelam o despreparo das organizaçóes laborais para recebê-los. Foi identificada a necessidade de superação nas barreiras físicas ou arquitetônicas e nas comunicacionais, com o provimento 
de linguagens especiais - Libras ou Braille — ou ainda nas atitudinais, na remoçáo do preconceito ou do estigma para com as pessoas com deficiências.

Percebeu-se que há uma incapacidade para lidar com os limites impostos pelas deficiências. Por vezes, os colegas de trabalho adotam uma postura tutorial sobre o processo laboral da pessoa com deficiências, ou seja, buscam "proteger aqueles que não são capazes de realizar determinada tarefa"; ou pior, disseminam uma cultura de "piedade" e "compaixão", causando incômodo às pessoas com deficiência. Ademais, como bem pontuado por Höfling (2001), a administração pública, pautada numa proposição crítica de Estado, deve atender a todos os segmentos sociais, não destacando um em detrimento do outro, no estabelecimento de programas de açáo de ampla magnitude, universalizantes, que propiciem, além do acesso, a participação dos sujeitos nas diversas instâncias; visando à garantia da igualdade dos direitos, independentemente do seu grupo social.

Nessa direção, investimentos em ações que superem concepçóes baseadas na piedade e no assistencialismo, com vistas ao respeito e à valorização da diversidade humana para a garantia dos direitos das pessoas com deficiências, se fazem necessários. Caso contrário, tem-se no Brasil o entendimento de que as medidas protetivas se configuram em benesses, e não em direitos adquiridos, levando os indivíduos de uma organização a tratarem esse grupo como seres incapazes e dignos de pena.

Logo, os resultados do presente estudo indicam a necessidade do desenvolvimento de programas educacionais com funcionários e gestores com o objetivo de modificar suas concepçóes acerca do trabalho das pessoas com deficiência, refletindo criticamente sobre as relaçóes estabelecidas com pares diferentes, na superação de práticas de cunho estritamente assistencialista. Toldrá, De Marque e Brunello (2010) pontuam que o desconhecimento e a desinformaçáa geram preconceitos e dificultam as oportunidades de participação das pessoas com deficiência no contexto laboral e, ao contrário, o acesso à informação adequada é considerado um poderoso instrumento de sensibilizaçáo para o desenvolvimento social e respeito à diversidade no trabalho.

Embora na percepção da maioria dos participantes da pesquisa (62\%) não haja significativa diferença entre o ambiente de trabalho em instituições públicas e privadas, dois fatores são interessantes de serem ressaltados. O primeiro diz respeito à atraçáo que o setor público exerce quando se trata da escolha do local para se exercer a atividade profissional, já que permanece a ideia de segurança legal adquirida através da carreira pública após o período de estágio probatório. O segundo fator é a percepção dos participantes (67\%) de que a recepção no posto de trabalho é melhor no setor privado, ou seja, a empresa privada tem maior autonomia para acolher melhor o trabalhador com deficiência. A explicaçáo se deve ao fato de que no setor público as regras burocráticas e os regulamentos administrativos que orientam o trabalho são menos flexíveis e, portanto, demoram mais para serem mudados, dependendo na maioria das vezes de alteraçóes legais para tanto. 
Especificamente no caso da universidade investigada, pouco mais da metade das pessoas com deficiência entrevistadas e que ali atuam (57\%) concorda que o posto de trabalho está adaptado às suas necessidades. Apesar disso, é importante ressaltar que a maior parte da amostra aqui considerada é composta por indivíduos que têm deficiências adquiridas, o que nos leva a refletir sobre o quanto as condições de trabalho já ofereciam oportunidades para o bom exercício profissional ou o quanto o ambiente se adaptou, posteriormente, para acomodarse à situação imposta.

Um último aspecto a ser analisado diz respeito à sensação de valorização que a pessoa com deficiência tem em seu ambiente de trabalho. Quase todos $(90 \%)$ os respondentes se sentem valorizados pela organizaçáo. Contribuem para essa sensação os salários competitivos, a segurança no emprego, as regras e os regulamentos claros e o alinhamento do posto de trabalho com a formação específica, pela adoção de procedimentos inerentes ao método de seleção para o ingresso, acesso por concurso público. É unânime o sentimento de satisfação com o posto de trabalho atual.

No entanto, no cotejo dos achados, é possível perceber certa dualidade no posicionamento dos participantes, pois se de um lado acreditam que a empresa de natureza privada apresenta maior autonomia e com isso pode atender melhor às especificidades de seus empregados, por outro lado, quase a totalidade aponta para a satisfação em atuar numa instituição governamental. Ainda, os respondentes apontam que o ambiente ainda não está totalmente adaptado às suas reais necessidades, talvez em função da aquisição de algum acometimento - em decorrência de doenças e/ou de acidentes, por exemplo - que levaram a apresentar necessidades diferentes no decurso do processo laboral. Tal fato parece indicar que a adaptação do trabalho ocorre mais em função do próprio trabalhador diante da sua nova realidade, do que por parte da organização.

\section{Considerações finais}

Dado tudo que foi exposto, é possível perceber que há uma tensão entre os elementos escolhidos por esta investigação, ou seja, a escola, o trabalho e as pessoas com deficiências, mas é inegável que, sejam as organizaçóes ou os indivíduos, há traços que apontam para a construção de uma sociedade mais inclusiva. Podemos questionar se o ritmo do processo poderia se acelerar, mas para isso certamente são necessários avanços materiais e culturais que determinam os comportamentos, as condutas e os regulamentos no convívio social.

Leis criadas no final do século passado, em nosso país, geraram inicialmente dúvidas e conflitos, principalmente quando olhamos para o am- 
biente escolar. Embora a tensão permaneça, o cotidiano educacional vem se adaptando, tornando-se mais natural a convivência entre os diferentes. Mesmo assim, é possível identificar, nos relatos colhidos, que há muito por fazer, particularmente no que diz respeito às atitudes eivadas de preconceito e à falta de preparo - humano, material e administrativo - para fornecer condiçóes que permitam formas mais elevadas de desenvolvimento da pessoa com deficiência. A título de exemplificação, na universidade investigada, o número de trabalhadores ultrapassa a somatória de 10 mil funcionários, entre docentes e técnico-administrativos, e recorda-se que foram informados 34 funcionários, identificados na condiçáo de pessoa com deficiência. Tais números retratam que mesmo que, apesar da promulgação de políticas públicas que indiquem medidas equitativas para favorecer condiçóes de igualdade aos direitos fundamentais - dentre eles destaca-se o trabalho por interesse do estudo - , muito há que se fazer para que a participação de pessoas com deficiência no mundo do trabalho formal se torne mais concreta.

Quanto ao nosso foco específico, ou seja, as condiçóes de trabalho oferecidas por uma instituição pública de Ensino Superior para a inclusão de pessoas com deficiências, sob a ótica de docentes e servidores técnico-administrativos que se encontram nessa condição, fica evidente que, regulamentado o acesso pela reserva de vagas, há que se cuidar da permanência para transformar o trabalho desse público em algo produtivo e criativo. Abrir canais de comunicação, de diálogo entre os diferentes no ambiente de trabalho acelera o processo de inclusão e diminui preconceitos. Para tanto, porém, o primeiro passo é identificar onde está esse servidor. Dados sobre sua presença e sobre suas necessidades, processos participativos de comunicação e desenho das atividades laborais e administraçáo porosa aos anseios dos trabalhadores (BIZELLI, 2013) são condições indispensáveis para que sejam traçadas políticas adequadas à construção de uma convivência laboral saudável.

Muito embora grande parte dos participantes deste estudo relate que se encontra satisfeita com seu emprego na universidade pública, os dados sistematizados apontam mais para focar nas condiçóes de trabalho gerais, como a garantia do posto em função da estabilidade laboral, do que no reconhecimento que a instituiçẫo tem frente às suas necessidades especiais, fato apontado por quase metade dos respondentes.

Tais indicativos nos levam a concordar com as consideraçóes de Violante e Leite (2011), em estudo sobre empregabilidade de pessoas com deficiência, que indicam que a análise da deficiência no contexto laboral pouco recai em uma perspectiva contextual, muitas vezes se limitando a enfocar no sujeito as possibilidades de reabilitação sem alteração no contexto. Tais açóes deixam de criar situaçôes de ajustes na esfera profissional que garantiriam a continuidade do exercício da função, ainda que em outras condiçôes. 
Do ponto de vista legal, o primeiro desafio que se coloca para a convivência pacífica dos desiguais na sociedade liberal é a existência da lei. Assim, no processo de construçáo do corpus normativo dentro de um Estado de Direito, regido por regras democráticas, sufragado pelas maiorias representativas, a regra jurídica ganha concretamente "facticidade" (HABERMAS, 1998). No entanto, todo o funcionamento da engenharia republicana, se não estiver respaldado por um corpo administrativo capaz de executar açóes facilitadoras do usufruto da cidadania ou açóes coercitivas contra o cerceamento do direito constitucional, não poderá evitar o descumprimento da lei, ou seja, recorrendo novamente a Habermas (1998), a norma não ganhará "validez".

Duas questóes se postulam para a sociedade que busca a disputa de interesses de forma civilizada nas sociedades modernas e desiguais (BIZELLI; CRUZ, 2014): (a) o combate da violência estrutural através do jogo político exige ambiente competitivo e regulado, racionalmente construído; minorias devem ser impedidas de manipular o espaço público e os meios de comunicação em favor próprio, subvertendo princípios de convivência equânime e pacífica, gerando arbitrariedades intoleráveis; (b) as estruturas administrativas devem estar permeáveis aos interesses de todos os cidadãos, garantindo os direitos fundamentais lavrados nas regras constitucionais do jogo, fortalecendo os atores e as arenas decisórias.

Portanto, não se trata apenas de considerar a falta de atenção com o deficiente no ambiente de trabalho, trata-se de perceber que se está diante de uma sociedade que avança no discurso e na construção discursiva do direito para todos, mas fecha suas portas — ou limita seletivamente a passagem de determinados grupos de interesse - de forma a garantir o direito para poucos. Talvez seja mais fácil visualizar a materialidade da exclusão no trabalho através da ótica dos deficientes.

Por fim, a vida profissional absorve grande parte do tempo vivido pelos indivíduos e os incrementos positivos no mundo do trabalho ganham importância por seus impactos na qualidade de vida dos seres humanos. Assim, vencer a visão isolacionista e competitiva das rotinas laborais; permitir o desenvolvimento profissional daquele que trabalha sob uma estrutura burocrática; vencer a fragmentação do trabalho e do trabalhador são aspectos importantes para garantir o funcionamento saudável da organização, mais ainda se ela configurar uma instituição que tem como objetivo o conhecimento científico.

A boa governança pública vai além das equações de alocação de recursos - humanos, financeiros e materiais - , ela permite vencer os preconceitos que impedem as sinergias no ambiente de trabalho. Liderar é vencer o desafio de estigmatizar o trabalhador por suas características particulares, oferecendo condiçóes de trabalho que ampliem as possibilidades dos seres humanos contribuírem para o aperfeiçoamento da organização ou, pelo menos, oferecer situaçóes que promovam uma competição menos predatória para aqueles que necessitam de auxílio especial. 


\section{Notas}

1. A noção de complementaridade causa certa tensão entre os teóricos da educação, já que muitos advogam uma independência do processo educativo frente ao mundo do trabalho, condição para que o próprio trabalho possa ser repensado de forma crítica e criativa.

2. Consideram-se apoios especiais: orientação, supervisão e ajudas técnicas, entre outros elementos que permitam compensar uma ou mais limitaçóes funcionais motoras, sensoriais ou mentais das pessoas com deficiências, de modo a superar barreiras da mobilidade e da comunicação, possibilitando plena utilização de capacidades em condiçóes de normalidade (BRASIL, 1999).

\section{Referências}

AMARAL, L.A. Sobre crocodilos e avestruzes: falando de diferenças físicas, preconceitos e sua superação. In: AQUINO, J.G. (Org.). Diferenças e preconceitos na escola: alternativas teóricas e práticas. São Paulo: Summus, 1998. p. 11-30.

BIANCHETTI, L. Aspectos históricos da apreensão e da educação dos considerados deficientes. In: ; FREIRE, I.M. (Orgs.). Um olhar sobre a diferença: interaçáo, trabalho e cidadania. Campinas: Papirus, 1998. p. 21-51. [Série Educação Especial].

BIZELLI, J.L. Inovação: limites e possibilidades para aprender na era do conhecimento. $1^{\text {a }}$ ed. Sáo Paulo: UNESP, 2013. v.1.

BIZELLI, J.L.; CRUZ, J.A.S. Notas introdutórias para discutir sobre os atores políticos e a transformação social. In: XXXVII CONGRESSO BRASILEIRO DE CIÊNCIAS DA COMUNICAÇÃO, 2014, Foz do Iguaçu. Anais... Foz do Iguaçu, INTERCOM, 2014. v. 1. p. 1-8.

BOBBIO, N. A era dos direitos. Rio de Janeiro: Campus, 1992.

BRASIL. Lei no 8.213, de 24 de julho de 1991. Dispóe sobre os Planos de Benefícios da Previdência Social e dá outras providências. Diário Oficial da União, Brasília, DF, p. 14809, 25 jul. 1991. Seção 1.

Lei no 8.742, de 7 de dezembro de 1993. Dispóe sobre a organizaçáo da Assistência Social e dá outras providencias. Diário Oficial da Uniāo, Brasília, DF, p. 18769, 8 dez. 1993. Seção 1.

Decreto $\mathrm{n}^{\circ} 3.298$, de 20 de dezembro de 1999. Regulamenta a Lei $\mathrm{n}^{\circ}$ 7.853, de 24 de outubro de 1989, dispóe sobre a Política Nacional para a Integração da Pessoa Portadora de Deficiência, consolida as normas de proteção, e dá outras providências. Diário Oficial da União, Brasília, DF, p. 19209, 25 out. 1999. Seção 1.

Lei $\mathrm{n}^{\circ} 10.098$, de 19 de dezembro de 2000. Estabelece normas gerais e critérios básicos para a promoção da acessibilidade das pessoas portadoras de deficiência ou com mobilidade reduzida, e dá outras providências. Diário Oficial da União, Brasília, DF, p. 2, 19 dez. 2000. Seção 1. 
CANDIDO PEREIRA, C.E. Inclusão no mercado de trabalho: analisando a relação escola e empregabilidade de pessoas com deficiências. 2010. 170f. Dissertação (Mestrado) Faculdade de Ciências e Letras, Universidade Estadual Paulista, Araraquara.

DALL'ACQUA, M.J.C. Intervenção no ambiente escolar: estimulação visual de uma criança com visão subnormal ou baixa visão. São Paulo: Unesp, 2002.

DOURADO, L.F.; OLIVEIRA, J.F. Políticas educacionais e reconfiguração da educação superior no Brasil. In: ; CATANI, A.M. Universidade pública: políticas e identidade institucional. Campinas: Autores Associados, 1999.

GOFFMANN, E. Estigma: notas sobre a manipulação da identidade deteriorada. Rio de Janeiro: Guanabara Koogan, 1988.

HABERMAS, J. Facticidad y validez. Madrid: Trotta, 1998.

HÖFLING, E.M. Estado e políticas (públicas) sociais. Cadernos CEDES, v. 21, n. 55, p. 30-41, 2001.

LOPES, E.M.C.; LEITE, L.P. Deficiência adquirida no trabalho em policiais militares: significados e sentidos. Psicologia \& Sociedade, v. 27, n. 3, p. 668-677, 2015.

MARTINS, S.E.S.O.; LEITE, L.L. As contribuiçôes da Educação Especial para promoção da educação inclusiva nas normativas brasileiras. Psicología, Conocimiento y Sociedad, v. 4, p. 189-2010-210, 2014.

MAZZOTTA, M.J.S. Educação especial no Brasil: história e políticas públicas. $5^{\mathrm{a}}$ ed. São Paulo: Cortez, 2005.

MIRANDA, T.G. Trabalho e deficiência: velhos desafios e novos caminhos. In: MANZINI, E.J. Inclusão e acessibilidade. Marília: ABPEE, 2006. p. 159-170.

PASTORE, J. Oportunidades de trabalho para portadores de deficiência. São Paulo: LTr, 2000.

PEREIRA, A.C.C.; PASSERINO, L. Um estudo sobre o perfil dos empregados com deficiência em uma organização. Revista Brasileira de Educação Especial, v. 18, n. 2, p. 245-264, 2012.

RAWLS, J. Uma teoria da justiça. São Paulo: Martins Fortes, 1997. [Tradução de Almiro Pisetta e Lenita M. R. Esteves].

ROSS, P.R. Trabalho das pessoas com deficiência: transformando barreiras em oportunidades. In: MANZINI, E.J. Inclusão e acessibilidade. Marília: ABPEE, 2006. p. 171-180.

SÃO PAULO. Lei Complementar Estadual no 683, de 18 de setembro de 1992. Dispóe sobre a reserva de vaga, nos concursos públicos, de percentual de cargos e empregos para portadores de deficiência e dá outras providências correlatas. Disponível em: <http:// governo-sp.jusbrasil.com.br/legislacao/179402/lei-complementar-683-92>. Acesso em: 20 mai. 2015.

SEN, A. Desigualdade reexaminada. Rio de Janeiro: Record, 2001.

SOUZA, A.I.J.; ALTHOFF, C.R.; RIBEIRO, E.M.; ELSEN, I. Construindo movimentos para o fortalecimento da família. Família, Saúde e Desenvolvimento, v. 8, n. 3, p. 265-272, 2006. 
TOLDRÁ, R.C.; DE MARQUE, C.B.; BRUNELLO, M.I.B. Desafios para a inclusão no mercado de trabalho de pessoas com deficiência intelectual: experiências em construção. Revista de Terapia Ocupacional da Universidade de São Paulo, v. 21, n. 22, p. 158-165, 2010.

VIOLANTE, R.R.; LEITE, L.P. A empregabilidade das pessoas com deficiência: uma análise da inclusão social no mercado de trabalho do município de Bauru, SP. Cadernos de Psicologia Social do Trabalho, v. 14, n. 1, p. 73-91, 2011.

UNESCO. Declaraçáo de Salamanca. Necessidades Educativas Especiais - NEE. In: CONFERÊNCIA MUNDIAL SOBRE NEE. Salamanca: UNESCO, 1994.

. Declaração Mundial sobre Educação para todos: plano de ação para satisfazer as necessidades básicas da aprendizagem. Jomtien: UNESCO, 1990.

Recebido em 30 de junho de 2015.

Aprovado em 04 de julho de 2016. 